\title{
2009/40
}

On efficiency, concentration and welfare

Nicolas Boccard 
CORE

Voie du Roman Pays 34

B-1348 Louvain-la-Neuve, Belgium.

Tel (32 10) 474304

Fax (32 10) 474301

E-mail: corestat-library@uclouvain.be http://www.uclouvain.be/en-44508.html 


\title{
CORE DISCUSSION PAPER
}

$2009 / 40$

\section{On efficiency, concentration and welfare}

\author{
Nicolas BOCCARD ${ }^{1}$
}

May 2009

\begin{abstract}
The welfare impact of a merger involves the market power offense and the efficiency defense. Salant et al. (1983) show that mergers among symmetric firms are unprofitable except for monopolization. We characterize the limit to this merger paradox in a simple linear Cournot oligopoly with asymmetric costs. Farrell and Shapiro (1990) provide sufficient conditions for a profitable merger to increase welfare but leave open whether it exists. We characterize the degree of cost asymmetry making a merger both profitable and socially desirable. Comparing rationalization and synergy within the efficiency defense, we show that for most industry structures, a rationalization merger is more likely to be welfare enhancing but a synergy merger is more likely to be profitable.
\end{abstract}

Keywords: merger, efficiency, concentration, welfare, antitrust, competition.

JEL Classification: L40, D43, D24

${ }^{1}$ Departament d'Economia, University of Girona, Spain.

Financial support from Ministerio de Educación y Ciencia (Programa Salvador de Madariaga) is gratefully acknowledged. The author thanks the Center for Operations Research and Econometrics (CORE) for hosting him during the final stage of writing this paper.

This paper presents research results of the Belgian Program on Interuniversity Poles of Attraction initiated by the Belgian State, Prime Minister's Office, Science Policy Programming. The scientific responsibility is assumed by the author. 



\section{Introduction}

\subsection{Overview}

Thousands of mergers and acquisitions occur every year, many of them drawing the attention of the media and antitrust authorities. The controversy around these concentration operations can be synthesized as follows: a merger is guilty of the market power offense but may be absolved by the efficiency defense.

In their pioneering paper, Salant et al. (1983) assess the market power effect of a merger and show, in a symmetric Cournot framework, that mergers are unprofitable except for monopolization. ${ }^{1}$ Because so many mergers are still profitable for their promoters (about half according to empirical studies), there would be a paradox unless cost saving efficiencies are systematically involved. This is commensurate with the ample evidence on large and persitent productivity differences among producers, even within narrowly defined industries. With respect to the literature extending Salant et al. (1983), our first contribution is to characterize the limit to the merger paradox in terms of marginal cost asymmetries (in the same linear Cournot oligopoly model).

Adopting a normative stance, Farrell and Shapiro (1990) analyze the welfare effects of an horizontal merger and provide sufficient conditions for a profitable merger to increase welfare. A positive quandary they do not address is whether there are actually any profitable mergers that are also welfare improving. As the merger paradox indicates, efficiencies must be involved; our second contribution is to characterize the degree of cost asymmetry that clears a merger in terms of welfare, thus addressing the aforementioned dilemma (in the linear Cournot oligopoly model).

Lastly, we contribute to the controversy surrounding the efficiency defense. Schumpeter (1942)'s famous notion of "creative destruction" is akin to rationalization whereby low-cost producers (or plants) gain market shares at the expense of high-cost ones, in a process of entry, exit, acquisition and mergers. In his defense of the efficiency motive for mergers, Williamson (1968) points at synergy whereby the newly merged firm successfully combines the previously independent assets and improve her technology. ${ }^{2}$ This seminal paper has given the synergy theoretical concept an edge in the aca-

\footnotetext{
${ }^{1}$ In the linear Cournot oligopoly model, they show that a profitable merger must gather at least $80 \%$ of the per-merger market shares.

${ }^{2}$ An example would be merging across borders to reduce uncertainty regarding output markets, input supply, political pressure or currency risks.
} 
demic literature on efficiency although rationalization prominently figures in the US merger guidelines and is prevalent in the empirical literature on mergers and productivity growth. Our model is simple enough to encompass both types of efficiencies and enable a fruitful comparison of their influence over the private profitability and the social desirability of a merger.

In the remnant of this introduction, we recall the methodological debate behind the efficiency defense of mergers. Then, we state our contribution and relate it to the literature. Lastly we detail our case for focusing on rationalization. The next section presents our analytical results while the third concludes.

\subsection{Efficiency Controversy}

Two doctrines of economic competition vie for intellectual leardership. The "Structure Conduct Performance" (SCP) paradigm, inspired by Bain (1951), focuses on allocative or static efficiency. It studies how firms compete simultaneously in current markets; its policy aim is to create workable competition for the present. The Chicago critic builds on Schumpeter (1942)'s concept of "creative destruction" and holds a dynamic view of efficiency; it studies how firms compete sequentially for the market and emphasizes innovation. A temporary monopoly that enables an innovator to recoup its investment is thus seen as a necessary evil on the path towards the higher goal of long term progress.

This controversy spills over the handling of concentration operations (mergers and acquisitions). The SCP paradigm holds a "market power" view along the following causal relationship: mergers increase firms' market power which leads to higher prices and hurts consumers. Since technologies and tastes are exogenously given, total welfare must also decrease. On that ground, significant mergers ought to be opposed.

The Chicago critic approaches mergers from two angles. The "efficiency defense" started by Williamson (1968) broadens the SCP's vision in asserting that mergers can contribute positively to welfare by bringing in efficiencies. It is also argued that the adequate criteria for antitrust authorities is (total) welfare rather than consumer surplus. More radically, Demsetz (1973) contends that the SCP confuses correlation and causation. ${ }^{3}$ True, there is a positive correlation between market concentration and industry profitability but which one drives the other cannot be identified with a comparative statics exercise, the very tool used by the SCP paradigm. The Chicago

\footnotetext{
${ }^{3}$ cf. also Dewey (1961), McGee (1971) and Peltzman (1977).
} 
schools then endorses a reverse causal chain: the more efficient (innovative) firms capture greater market shares, earn more and tend to buy out the less efficient firms (or drive them out of the market). The policy implication with respect to mergers is also reversed: allowing innovative firms to acquire obsolete ones promotes efficiency and ultimately welfare.

The academic debate spills over the real world as it influences the antitrust perception of mergers. Kovacic and Shapiro (2000) recall that until the 1970s, antitrust practitioners were in agreement with the "market power" view and sought to protect consumers from monopolization. The "efficiency defense" of mergers has then overcome initial defiance and become increasingly accepted by antitrust authorities and courts (cf. $\S 4$ in DoJ (1997) and §VII in EC (2004)). In a world where globalization has triggered mergers waves of dimensions unseen before, it is of the essence to understand the interplay between the two opposing views of efficiencies when assessing a merger.

\subsection{Contribution}

Our contribution is foremost a positive complement to the normative study of Farrell and Shapiro (1990) (henceforth FS). Using the standard staple of industrial organization, the linear Cournot model of oligopoly (e.g., Salant et al. (1983)), we show how the efficiency defense interacts with the market power offense. ${ }^{4}$ In our static setting without entry nor exit, firms are either advanced (cutting-edge) or obsolete. The percentage welfare loss due to a switch from the efficient to the inefficient technology in the entire industry is called the technological gap; it is our measure of the technological asymmetry among members of the industry. We focus on bilateral mergers since other combinations are seldom observed. ${ }^{5}$

We start with the study of a rationalization merger whereby a cuttingedge firm buys out an obsolete one. Proposition 1 shows that a mild technological gap is sufficient for a rationalization merger to be welfare improving. This means that the loss of consumer surplus resulting from the global output contraction can be compensated by the profit increase of efficient firms (the merging one and the outsiders to the deal). The condition can also be

\footnotetext{
${ }^{4}$ As we emphasize in the conclusion, our findings should not be taken at face value when assessing actual merger cases given the highly stylized nature of our framework.

${ }^{5}$ This is probably due to the contracting costs of negotiation among shareholders. As far as theory is concerned, a merger among many firms can still be decomposed into successive bilateral mergers upon which our analysis can be applied (cf. Pesendorfer (2005) for stylized facts).
} 
checked from market observables: the output of the absorbed obsolete firm must be less than the total excess output of efficient firms. ${ }^{6}$

Proposition 2 characterizes the minimum technological gap making a rationalization merger (privately) profitable; it turns out to be larger than the previous one. The reason is the one at the root of the merger paradox: the merged firm produces less than the combined output of merger participants; a strong rationalization is thus needed to compensate for the relative profit loss. Proposition 3 then restates a previously known outcome: a privately profitable merger involving at most half the industry is socially desirable. In our linear setting, the condition boils down to an industry count of at least 5 firms or exactly 4 with at least 2 efficient. Our main result regarding rationalization mergers (Corollary 1 ) is then the combination of these preliminary steps assuming the industry counts 5 or more firms. If the technological gap is

- small: no one wants to merge; this is socially desirable.

- medium: no one wants to merge but a rationalization merger would increase welfare.

- large: an efficient firm agrees to buy an obsolete one which is welfare increasing.

- huge: obsolete firms are expelled from the market by efficient ones.

Given the competing roles of synergy and rationalization as alternatives forms of efficiency, it is worthwhile to compare them in our limited framework. Proposition 4 characterizes the technological gap above which a synergy merger is profitable and raise welfare. We then show in Corollary 2 that for most industry structures, a rationalization merger is more likely to be welfare enhancing but a synergy merger is more likely to be profitable.

Lastly, we take a look at within-firm innovation as the ability to upgrade technology from obsolete to cutting-edge. We obtain very intuitive results: firstly, it is privately and socially desirable for an obsolete firm to become cutting-edge, secondly two obsolete firms won't merge if they cannot innovate.

\subsection{Literature}

Cournot (1838) introduces the model of quantity competition and observes that a firm with low marginal cost produces more than higher-cost firms,

\footnotetext{
${ }^{6}$ Individual excess output is the difference in production between an efficient and obsolete firm.
} 
and that some of them might be forced to exit. ${ }^{7}$ He also notices that a given total industry output would be produced at higher cost by competing asymmetric producers than if a monopolist made their production decisions (because their marginal costs are not equal at equilibrium).

Williamson (1968) exploits this intuition and shows that if a merger generates a synergy (i.e., marginal cost reduction) then the welfare loss due to the price increase may be compensated by the cost saving. Although the original model is crude, the intuition is so strong that it remains robust to generalizations.

Cowling and Waterson (1976) show in a Cournotian model that the average profit-revenue ratio is equal to the concentration-elasticity ratio. Although no causality can be deduced from this formula, it has been adopted as a foundation for the "market power" rationale. Clarke and Davies (1982) further show that the Herfindhal concentration index increases with the variance of firms' marginal costs; this proves that concentration is greater when some firms have a cost advantage, a result that lands support to the dynamic efficiency rationale. In the same vein, Salant and Shaffer (1999) show that if the average marginal costs in the industry is constant, then so is aggregate output and consumer surplus. When a shock makes such an industry more cost-asymmetric, concentration, aggregate profit and welfare all increase together. ${ }^{8}$ This finding provides a rationale for government support of "national champions" at the expense of other domestic firms with the same initial technology.

Salant et al. (1983) address the profitability of mergers in the Cournot oligopoly with symmetric marginal cost and show that except for monopolization, mergers are unprofitable. This paradox points at synergies or scale economies as the real motive for mergers. FS further develop the Cournot model by considering asymmetric technologies. They characterize market structures where a concentration operation raises welfare and price simultaneously. Yet, they do not to put cost asymmetries and rationalization at the forefront since they moslty deal with synergies. As already explained, our work aims at filling this gap.

To show that concentration can be socially beneficial, Daughety (1990) studies symmetrical firms that behave asymmetrically à la Stackelberg: part of the industry commits to its output at some point whereas the rest does

\footnotetext{
${ }^{7}$ The properties enunciated in this paragraph are proved in the appendix.

${ }^{8}$ The intuition lies in the fact that individual profit is convex increasing in output, thus convex decreasing in marginal cost. This means that every firm is a risk-lover when it comes to draw a technology from a distribution with fixed mean (cf. Février and Linnemer (2004) for a generalization).
} 
so later on (apart of which all are Cournot players). ${ }^{9}$ Huck et al. (2004) refine the argument with the idea of "commitment by governance" whereby the new firm's owner forces the managers of the formerly independent units to behave as leader and follower.

In the EU, the "safe harbor" condition bestows immunity from antitrust scrutiny if combined market shares are below 50\% (cf. Parisi (2007) §III.D). Levin (1990) rationalizes it by considering a Cournot oligopoly among symmetric firms yet allowing the merged firm to behave differently afterwards. ${ }^{10}$ Heubeck et al. (2006) improve on this feature by sticking to Cournot behavior and introducing a unique cutting-edge firm; their model is thus a particular case of ours. They compute the minimum number of merger candidates making a merger profitable and then the maximum number of merger candidates consistent with a welfare increase. The authors only prove that the two conditions are compatible with the help of a graphical plot. A shortcoming of their approach is to focus on "many firms" mergers which is a scarcely observed phenomenon. They however point out that cost efficiencies as well as the entire cost structure of the industry matter when assessing the welfare effect of a merger, a claim we are able to confirm.

Within the trade literature, a number of papers use a framework close to ours when studying international mergers but their focus is on the impact of tariff reductions (e.g. Benchekroun and Chaudhuri (2006)). An exception is Neary (2007) who considers rationalization mergers and derives our proposition 2. Similarities and differences with our work are highlighted in the text.

The literature cited up to this point emphasizes the normative aspect of mergers. There also exists a positive literature dealing with entry and merger waves, topics which fall out of the scope of our simple static oneshot game. Kamien and Zang (1990) show that monopolization is not to be expected because early acquirees require a too high price from the acquirer in anticipation that the final conglomerate will be highly profitable. More recently, Pesendorfer (2005) considers the case where a merger may lead to additional mergers in the future; his results tend to oppose those of static models. The impact of potential entry on merger profitability is taken on by Werden and Froeb (1998), Spector (2003), and Davidson and Mukherjee

\footnotetext{
${ }^{9}$ The author motivates this unorthodox choice by stating rather bluntly "I take as given that firms may find (this) asymmetry advantageous".

${ }^{10}$ The author does not explain how this change of behavior comes about. It is also noticeable that all his results are out-of-equilibrium comparative static exercises, that is to say, the preconditions may well never take place so that the conclusions may well never matter.
} 
(2007). Endogenous mergers are studied by Qiu and Zhou (2007) for rationalization and by Motta and Vasconcelos (2005) and Banal Estañol et al. (2008) for synergies.

\subsection{Rationalization}

The efficiency improvement at the core of Schumpeter (1942)'s concept of "creative destruction" is rationalization. The latest US merger guidelines, which is the outcome of decades of practice, acknowledges this vision when it signals rationalization as the most substantial efficiency (cf. production reshuffling in $\S 4$, DoJ (1997)). ${ }^{11}$ In his chapter for the Handbook of Industrial Organization, Whinston (2007) confirms the practical importance of rationalization ( $\mathrm{p}$ 2385) when stating: at an empirical level, oligopolistic industries (i.e., those in which mergers are likely to be scrutinized) often exhibit substantial variation in marginal cost across firms... A potentially significant source of welfare variation arising from a horizontal merger is ... the welfare changes arising from shifts of production across firms that have differing marginal costs; so-called, "production reshuffling".

Synergies and scale economies also suffers from a weak theoretical underpinning as recognized by Farrell and Shapiro (2001) when stating (p 5) that claimed synergies are double-edged: the same conditions that tend to make synergies more merger-specific and more beneficial to consumers also tend to make the merger itself more problematic. In that respect, scale economies and buyer power are suspicious since they can often be achieved unilaterally. True synergies, in turn, are based on complementarities which makes the merger non horizontal and rather similar to vertical integration. Lastly, these efficiencies bear no relation to the mode or intensity of market competition. This means that any welfare loss due to "market power" can be compensated by a large enough add-hoc synergy or scale economy. ${ }^{12}$

The empirical literature also support rationalization vs. synergies when analyzing mergers and the general pace of industry change. In their international study, Gugler et al. (2003) find that mergers increase profits and lose market shares. Empirically, $29 \%$ of mergers are profitable and welfareenhancing, $28 \%$ are unprofitable and inefficient, $27 \%$ are profitable and inef-

\footnotetext{
${ }^{11}$ Although a merger strengthening a dominant position is to be barred, authorities make an exception when the target is in hardship; this is the failing firm defense in the $\mathrm{US}$ and the rescue merger in the EU. This lenient policy is a recognition of the positive welfare effect of rationalization.

${ }^{12}$ This is actually what managers claim to gain regulatory and shareholder approval. In many cases such as Daimler-Chrysler, the acquirer ends-up reselling the target because the synergies fail to materialize.
} 
ficient, the remaining $15 \%$ being unprofitable but efficiency-enhancing (irrational mergers undertaken by hubristic CEOs). Pesendorfer (2003), studying the paper industry, observes also that merged firms are more likely to scrap capacity subsequent to an acquisition, in accordance with rationalization. Also, a majority of acquiring firms achieve an efficiency increase following an acquisition, in accordance with synergy. Gugler and Siebert (2007) provide similar evidence from the semiconductor industry.

As summarized by Foster et al. (2008), a robust finding of studies based on business-level microdata is that within-industry reallocation and its associated firm turnover contributes substantially to industry productivity growth. The main driver of aggregate productivity changes is the reallocation of market shares to more efficient producers, either through market share shifts among incumbents, M\&A or through entry and exit. ${ }^{13}$

\section{A Model of Horizontal Merger}

\section{$2.1 \quad$ Specifications}

A market for an homogeneous product has linear demand $D(p)=M-$ $p .{ }^{14}$ Since the empirical literature reports large and lasting productivity differences among plants (within an industry), we consider advanced (a) versus bygone $(b)$ technologies or in efficiency terms, cutting-edge versus obsolete. For $i=a, b$, there are $n_{i}$ active firms with the same constant marginal cost $c_{i}$ and zero fixed cost. We let $n \equiv n_{a}+n_{b}$ denote the total number of firms and $c \equiv \frac{c_{a} n_{a}+c_{b} n_{b}}{n_{a}+n_{b}}$ the average (egalitarian) marginal cost of the industry.

The marginal cost gap $\delta \equiv c_{b}-c_{a}>0$ can be seen as a consequence of past choices regarding $\mathrm{R} \& \mathrm{D}$ or internal organization (Salant et al. (1983) use $\delta=0)$. We let $Q_{a}^{*} \equiv M-c_{a}$ and $Q_{b}^{*} \equiv Q_{a}^{*}-\delta$ be the efficient (competitive) market outputs under the uniform use of each of the two technologies. We then define the technological gap as the dimensionless ratio $\gamma \equiv 2 \frac{Q_{a}^{*}-Q_{b}^{*}}{Q_{b}^{*}}=$ $\frac{2 \delta}{M-c_{b}}$ which is approximatively the welfare loss due to the use of the obsolete technology (over the efficient one). ${ }^{15}$ Indeed, the maximum welfare with the

\footnotetext{
${ }^{13}$ cf. also Bartelsman and Doms (2000) and Melitz (2003).

${ }^{14}$ In such a simple setting, there is no loss of generality in using a unitary slope since all cost terms can be rescaled to achieve it.

${ }^{15}$ Qiu and Zhou (2007) use the market size $M$ as their main parameter for static comparative purposes.
} 
efficient and obsolete technologies is $W_{i}^{*}=\left(Q_{i}^{*}\right)^{2}$ for $i=a, b$, thus

$$
\frac{W_{a}^{*}-W_{b}^{*}}{W_{b}^{*}}=\frac{2 Q_{b}^{*}+\delta}{Q_{b}^{*}} \frac{Q_{a}^{*}-Q_{b}^{*}}{Q_{b}^{*}} \simeq \gamma
$$

Let us first characterize the equilibrium in the Cournot game of quantity competition. The FOCs of profit maximization are

$$
\begin{aligned}
& 2 q_{a}=M-c_{a}-\left(n_{a}-1\right) q_{a}-n_{b} q_{b} \\
& 2 q_{b}=M-c_{b}-\left(n_{b}-1\right) q_{b}-n_{a} q_{a}
\end{aligned}
$$

so that the equilibrium individual quantities are

$$
q_{a}=\frac{M-c_{a}+\delta n_{b}}{n+1} \quad \text { and } \quad q_{b}=\frac{M-c_{b}-\delta n_{a}}{n+1}
$$

where we notice the production wedge $q_{a}-q_{b}=\delta$. Obsolete firms participate only if

$$
q_{b}>0 \Leftrightarrow M-c_{b}>\delta n_{a} \Leftrightarrow \gamma<\frac{2}{n_{a}}
$$

a condition which we shall assume to hold. ${ }^{16}$

Total equilibrium quantity is $Q \equiv n_{a} q_{a}+n_{b} q_{b}=\frac{n}{n+1}(M-c)$ while the equilibrium price is $p=\frac{M+c n}{n+1}$. As usual with Cournot competition, it can be checked that the individual profit is $\pi_{i}=q_{i}^{2}$ for $i=a, b$. This means that firms are looking forward to expand their sales. We define the profit aggregates $\Pi_{i} \equiv n_{i} \pi_{i}$ for $i=a, b$. Since consumer surplus is $S(Q)=\frac{1}{2} Q^{2}$, total welfare is $W=S+\Pi_{a}+\Pi_{b}$.

\subsection{Price effect of a merger}

Upon merging an efficient firm to an obsolete one, we have $n_{a}^{\prime}=n_{a}$ and $n_{b}^{\prime}=n_{b}-1$ since the new owner will use exclusively the efficient technology i.e., shuts down the obsolete plant. The output changes between the old and new equilibrium computed using (2) are $\Delta q_{b}=\Delta q_{a}=\frac{q_{b}}{n}>0$ i.e., the increased concentration benefits all remaining firms. Yet one obsolete firm has been shut down so that the aggregate change is $\Delta Q=(n-1) \frac{q_{b}}{n}-q_{b}=$ $-\frac{q_{b}}{n}<0$. We have thus shown,

Lemma 1 Acquisition of an obsolete firm by an efficient one raises the market price.

\footnotetext{
${ }^{16}$ In the presence of many firms, if obsolete ones start to acquire the efficient technology $\left(n_{b} \searrow, n_{a} \nearrow\right)$, there is a threshold at which (3) ceases to hold i.e., all the remaining obsolete firms are forced to exit. At this point, concentration would increase sharply.
} 
Lemma 1 is a particular case of FS's Proposition 2 (p. 112) stating that "If a merger generates no synergies, then it causes price to rise". The proof here shows that no matter how strong the technological asymmetry, the indirect improvement of the industry cost structure falls short of compensating the direct effect of losing one producer. In the symmetric technologies case, there is no indirect effect so that concentration reduces output and thus welfare (recall that market output is then an exhaustive indicator of welfare).

\subsection{Welfare effect of a merger}

The changes in the various elements constitutive of the welfare are

$$
\begin{aligned}
\Delta S & =\left(Q+\frac{1}{2} \Delta Q\right) \Delta Q=-\left(n_{a} q_{a}+n_{b} q_{b}-\frac{q_{b}}{2 n}\right) \frac{q_{b}}{n} \\
\Delta \Pi_{a} & =n_{a}\left(2 q_{a}+\Delta q_{a}\right) \Delta q_{a}=n_{a}\left(2 q_{a}+\Delta q_{a}\right) \frac{q_{b}}{n} \\
\Delta \Pi_{b} & =\left(n_{b}-1\right)\left(q_{b}+\Delta q_{b}\right)^{2}-n_{b} q_{b}^{2}=\left(n_{b}-1\right)\left(2 q_{b}+\Delta q_{b}\right) \Delta q_{b}-q_{b}^{2} \\
& =q_{b}^{2}\left(\left(n_{b}-1\right)\left(2+\frac{1}{n_{a}+n_{b}}\right) \frac{1}{n_{a}+n_{b}}-1\right)=\frac{1}{n} q_{b}^{2}\left(n_{b}-n_{a}-1-\frac{\left.n_{a}+(6)\right)}{n}\right.
\end{aligned}
$$

Since all variations in $(4),(5),(6)$ are proportional to $\frac{q_{b}}{n}$,

$$
\begin{aligned}
\Delta W & \propto-\left(n_{a} q_{a}+n_{b} q_{b}-\frac{q_{b}}{2 n}\right)+n_{a}\left(2 q_{a}+\frac{q_{b}}{n}\right)+\left(n_{b}-n_{a}-1-\frac{n_{a}+1}{n}\right) q_{b} \\
& =n_{a} q_{a}-\left(n_{a}+1+\frac{1}{2 n}\right) q_{b}=n_{a} \delta-\left(1+\frac{1}{2 n}\right) q_{b}
\end{aligned}
$$

Let us interpret (7) using the rightmost expression. The first term is the positive welfare balance brought about by efficient firms whereas the negative second term is slightly more than the output of the obsolete mothballed firm. In equilibrium, an efficient firm produces more than an obsolete one; let us call "output gap" the difference $q_{a}-q_{b}=\delta$. We have thus an intuitive condition for a merger between two asymmetric firms to be welfare improving: the combined output gap of all efficient firms $n_{a} \delta$ is slightly larger than the output of the retired obsolete firm. Fulfillment requires either that efficient firms are numerous enough or that their cost advantage is large enough to overcome the output loss of the retired obsolete firm. Using (2), we can rearrange (7) in terms of the fundamentals of the model:

$$
\begin{aligned}
\Delta W>0 & \Leftrightarrow n_{a}\left(M-c_{a}+\delta n_{b}\right)>\left(M-c_{b}-\delta n_{a}\right)\left(n_{a}+1+\frac{1}{2 n}\right) \\
& \Leftrightarrow n_{a}\left(M-c_{b}+\delta\left(n_{b}+1\right)\right)>\left(M-c_{b}-\delta n_{a}\right)\left(n_{a}+1+\frac{1}{2 n}\right) \\
& \Leftrightarrow\left(M-c_{b}\right)\left(1+\frac{1}{2 n}\right)>\delta n_{a}\left(n+2+\frac{1}{2 n}\right) \\
& \Leftrightarrow \frac{2 \delta}{M-c_{b}}=\gamma \quad>\quad \lambda_{a, b} \equiv \frac{2}{n_{a}} \frac{1+2 n}{1+4 n+2 n^{2}}
\end{aligned}
$$

We have thus shown, 
Proposition 1 Acquisition of an obsolete firm by an efficient one raises welfare if and only if the technological gap is larger than the threshold $\lambda_{a, b}$.

Compatibility with the condition for participation of obsolete firms is achieved since $\lambda_{a, b}<\frac{2}{n_{a}}$ (cf. eq. (3)). Table 1 in the Appendix displays the rather low percentage values of the threshold $\lambda_{a, b}$ for combinations of obsolete $(b)$ and cutting-edge $(a)$ firms.

\subsection{Profitability of a merger}

Stigler (1950) famously said that "the promoter of a merger is likely to receive much encouragement from each firm, ..., except participation"; this is because in the present framework, there is more to gain by remaining an outsider to a merger rather than being an insider. ${ }^{17}$ To avoid complications, we disregard such an anticipation and study the profitability of a merger among myopic firms i.e., we focus on exogenous mergers instead of endogenous ones.

For a merger between two asymmetric firms, the profit change from the pre to the post merger situation is

$$
\begin{aligned}
\Omega & \equiv \pi_{a}^{\prime}-\pi_{a}-\pi_{b} \quad=\left(q_{a}+\frac{q_{b}}{n}\right)^{2}-q_{a}^{2}-q_{b}^{2} \\
& =\frac{2 q_{a} q_{b}}{n}-\left(1-\frac{1}{n^{2}}\right) q_{b}^{2}=\frac{q_{b}}{n^{2}}\left(2 n q_{a}-\left(n^{2}-1\right) q_{b}\right)
\end{aligned}
$$

Using (2), we can rearrange (9) as

$$
\begin{aligned}
\Omega>0 & \Leftrightarrow 2 n\left(M-c_{b}-\delta+\delta n_{b}\right)>\left(n^{2}-1\right)\left(M-c_{b}-\delta n_{a}\right) \\
& \Leftrightarrow\left(M-c_{b}\right)\left(n^{2}-2 n-1\right)<\delta\left(n\left(2 n_{b}+n n_{a}\right)-2 n-n_{a}\right) \\
& \Leftrightarrow \frac{2 \delta}{M-c_{b}}=\gamma \quad>\quad \mu_{a, b} \equiv 2 \frac{n^{2}-1-2 n}{2 n\left(n_{b}+1\right)+\left(n^{2}-1\right) n_{a}}
\end{aligned}
$$

We have thus shown,

Proposition 2 Acquisition of an obsolete firm by an efficient one is privately profitable if and only if the technological gap is larger than the threshold $\mu_{a, b}$.

This proposition is independently derived by Neary (2007) who interprets it as the technology gap between two countries (e.g., advanced vs. developing) that triggers cross border mergers. Table 2 in the Appendix illustrates the technological gap required for (10) to hold. We also notice in the last row the compatibility of (10) with the condition (3) for participation of obsolete firms.

\footnotetext{
${ }^{17}$ This observation is at the root of Salant et al. (1983)'s well known merger paradox.
} 


\subsection{Private vs. Social suitability of a merger}

To find out under what circumstances a price raising merger (between firms \#1 and \#2) nevertheless increases welfare, FS uses the "external effect" approach: they presume a privately beneficial merger and then proceed to derive a sufficient condition on pre-merger market shares; they obtain

$$
\frac{q_{1}+q_{2}}{Q} \leq-\sum_{i \geq 3} \frac{q_{i} \mathrm{~d} q_{i}}{Q \mathrm{~d} Q}
$$

In the general Cournot model with constant returns to scale for the nonmerging firms, it can be shown that $\frac{q_{1}+q_{2}}{Q} \leq \frac{1}{2}$ is a sufficient condition for (11). For a linear demand, this condition is also necessary. Thus, quoting FS,

Lemma 2 A privately profitable merger involving at most half the industry is socially desirable.

For policy purposes, the "external effect" approach is attractive as it enables to elude the computation of the merger efficiency which is a private information hardly accessible to antitrust authorities. However, this method has a serious drawback in that the presupposition might be empty in which case Lemma 2 is a void statement. FS recognize this risk when applying (11) to Salant et al. (1983)'s linear symmetric Cournot model where it is well known that a profitable merger must involve at least $3 / 4$ of the industry. ${ }^{18}$ In our model, it is possible to solve the issue analytically. A privately profitable merger is welfare improving if $\mu_{a, b} \geq \lambda_{a, b}$

$$
\begin{aligned}
& \Leftrightarrow \quad 0 \leq n_{a}\left(n+2+\frac{1}{2 n}\right)\left(n-\frac{1}{n}-2\right)-\left(1+\frac{1}{2 n}\right)\left(2\left(n_{b}+1\right)+\left(n-\frac{1}{n}\right) n_{a}\right) \\
& \Leftrightarrow \quad 0 \leq n_{a}\left(n_{a}+1\right)\left(n_{a}-3\right)-1+n_{a} n_{b}^{2}+2 n_{b}\left(n_{a}^{2}-n_{a}-1\right)
\end{aligned}
$$

whose solution is $n_{a}+n_{b} \geq 5$ or $\left(n_{a}+n_{b}=4\right.$ and $\left.n_{a}>1\right) .{ }^{19}$ Notice then that the solution to (12) agrees with (11) i.e., in all acceptable combinations $\left(n_{a}, n_{b}\right)$, the pre-merger combined market share of an efficient and an obsolete firm is less than $50 \%$. We have thus shown,

\footnotetext{
${ }^{18}$ One must take care of not interpreting Lemma 2 as: a merger involving at most half the industry is socially desirable but won't materialize because it is not profitable for its promoters.

${ }^{19}$ The relevant root of $(12)$ is $n_{b}=f\left(n_{a}\right) \equiv \frac{n_{a}-n_{a}^{2}+1+\sqrt{3 n_{a}+2 n_{a}^{2}+1}}{n_{a}}$ which satisfies $f(1) \simeq$ $3.4, f(2) \simeq 1.4, f(3) \simeq 0.1$ and $f\left(n_{a}\right)<0$ for $n_{a}>3$. Since $n_{i} \geq 1$ for $i=a, b$, the result follows.
} 
Proposition 3 The privately profitable acquisition of an obsolete firm by an efficient one is welfare enhancing if and only if the industry counts at least 5 firms or exactly 4 of which at least 2 are efficient.

Proposition 3 is a corollary of Lemma 2 recalling us that in the linear Cournot setting, firms tend to be of equal size, even in the presence of cost asymmetries. Hence, only four market structure combinations of obsolete and efficient firms are eliminated (cf. underlined entries in Table 2). In other words, almost any privately profitable merger is socially desirable if the industry has at least five participants. Bringing together our propositions, we obtain:

Corollary 1 In an industry whose structure satisfies (12), if the technology gap is

- $\gamma \leq \lambda_{a, b}$ : a merger is unprofitable and a source of dead weigth loss.

- $\lambda_{a, b}<\gamma \leq \mu_{a, b}$ : a merger is welfare enhancing but still unprofitable.

- $\mu_{a, b}<\gamma \leq \frac{2}{n_{a}}$ : a merger is welfare enhancing and profitable.

- $\gamma>\frac{2}{n_{a}}$ : obsolete firms are expelled from the market by efficient ones.

The contraposition of Corollary 1 is that some profitable mergers are welfare regressive contrary to Neary (2007)'s claim p1244 that "since only high-cost firms are eliminated, the increase in production efficiency ensures that the rise in profits dominates the fall in consumer surplus." ${ }^{20}$ This will be the case for the underlined entries of Table 2 when $\gamma>\mu_{a, b}$.

\subsection{Synergy}

Given the competing roles of synergy and rationalization as alternatives forms of efficiency, it is worthwhile comparing them in our framework. Although the US merger guidelines singles out rationalization as the prime source of efficiency, it also contemplates synergies when considering the possibility for two obsolete firms to merge and thereby succeed to upgrade their technology ${ }^{21}$ which we refer to as a catching-up merger.

\footnotetext{
${ }^{20}$ Neary (2007) only states the claim and refers the reader to Lahiri and Ono (1988) but in this latter article, the exact computation is absent.

${ }^{21}$ cf. DoJ (1997): "For example, merger-generated efficiencies may enhance competition by permitting two ineffective (e.g., high cost) competitors to become one effective (e.g., lower cost) competitor." The newly merged firm could even leapfrog the current best technology.
} 
In this situation, we have $n_{a}^{\prime}=n_{a}+1$ and $n_{b}^{\prime}=n_{b}-2$. Using the individual output formulas (2), we find $\Delta q_{a}=\Delta q_{b}=-\Delta Q=\frac{q_{b}-\delta}{n} \equiv z$. The changes in the various elements constitutive of the welfare are

$$
\begin{aligned}
\Delta S & =\left(Q+\frac{1}{2} \Delta Q\right) \Delta Q=-\left(Q-\frac{1}{2} z\right) z \\
\Delta \Pi_{a} & =\left(n_{a}+1\right)\left(2 q_{a}+\Delta q_{a}\right) \Delta q_{a}+q_{a}^{2}=n_{a}\left(2 q_{a}+z\right) z+q_{a}^{2} \\
\Delta \Pi_{b} & =\left(n_{b}-2\right)\left(2 q_{b}+\Delta q_{b}\right) \Delta q_{b}-2 q_{b}^{2}=\left(n_{b}-2\right)\left(2 q_{b}+z\right) z-2 q_{b}^{2}
\end{aligned}
$$

thus $\Delta W=z\left(\frac{1}{2} z-Q+n_{a}\left(2 q_{a}+z\right)+\left(n_{b}-2\right)\left(2 q_{b}+z\right)\right)+q_{a}^{2}-2 q_{b}^{2}=\Phi z+$ $B$ with

$$
\begin{aligned}
& B \equiv q_{a}^{2}-2 q_{b}^{2}=\left(q_{a}+2 q_{b}\right)\left(q_{a}-2 q_{b}\right)=-\left(3 q_{b}+\delta\right)\left(q_{b}-\delta\right)=-\left(3 q_{b}+\delta\right) n z \\
& \Phi \equiv \frac{1}{2} z-Q+n_{a}\left(2 q_{a}+z\right)+\left(n_{b}-2\right)\left(2 q_{b}+z\right)=Q-4 q_{b}+z\left(n-\frac{3}{2}\right)
\end{aligned}
$$

so that expanding $z$ we obtain

$$
\begin{aligned}
\frac{\Delta W}{z} & \propto n_{a} q_{a}+n_{b} q_{b}-4 q_{b}+\frac{q_{b}-\delta}{n}\left(n-\frac{3}{2}\right)-\left(3 q_{b}+\delta\right) n \\
& =n_{a} \delta+n q_{b}-\left(3 q_{b}+\delta\right)-\frac{3}{2} \frac{q_{b}-\delta}{n}-\left(3 q_{b}+\delta\right) n \\
& =\delta\left(\frac{3}{2 n}-1-n_{b}\right)-q_{b}\left(2 n+3+\frac{3}{2 n}\right)<0 \quad \text { since } \frac{3}{2 n}<1+n_{b}
\end{aligned}
$$

We now look at private profitability. To the extend that the emulation of the advanced technology is costless or free of charge, the profitability of a synergy merger is given by

$$
\Upsilon \equiv q_{a}^{\prime 2}-2 q_{b}^{2} \propto q_{a}^{\prime}-2 q_{b}=\Delta q_{a}+q_{a}-2 q_{b}=z-\left(q_{b}-\delta\right)=-(n-1) z
$$

thus has the same sign as $\Delta W$. To conclude $\Delta W>0$ and $\Upsilon>0$ if and only if

$$
z<0 \quad \Leftrightarrow \quad q_{b}<\delta \quad \Leftrightarrow \quad \gamma \quad>\quad \rho_{a, b} \equiv \frac{2}{2 n_{a}+n_{b}+1}
$$

using again formula (2). We have thus shown,

Proposition 4 A catching-up synergy merger is profitable and raises welfare if and only if the technological gap is larger than the threshold $\rho_{a, b}$.

We can now compare synergy and rationalization mergers in their relation to existing cost asymmetries in the industry. Regarding profitability, it is a matter of algebra to show that $\mu_{a, b}-\rho_{a, b}$ is proportional to $n(n-4)-1$; it is thus positive if and only if $n \geq 5$. Regarding welfare, we can show that $\rho_{a, b}-\lambda_{a, b}$ is proportional to $2 n\left(n_{a}-1\right)-1$; it is thus positive if and only if $n_{a}>1$. To cluster these findings assume $n \geq 5$ and $n_{a}>1$ so that $\lambda_{a, b}<\rho_{a, b}<\mu_{a, b}$ is true. For a small technology gap $\left(\lambda_{a, b}<\gamma<\rho_{a, b}\right)$, both 
types of mergers are unprofitable but the rationalization merger is welfare enhancing. For an intermediate technology gap $\left(\rho_{a, b}<\gamma<\mu_{a, b}\right)$, both types of mergers are welfare enhancing but only the synergy merger is profitable. In other words, welfare increases faster with the technology gap under rationalization whereas profitability increases faster with the technology gap under synergy. Summarizing, we obtain the following corollary:

Corollary 2 In an industry counting at least five firms of which more than one is advanced, a rationalization merger is more likely to be welfare enhancing but a synergy merger is more likely to be profitable.

Another way to explain why a synergy merger can be profitable is to reason that it is analytically equivalent to the following two-step procedure: an obsolete firm innovates which is both welfare improving and profitable (cf. Proposition 5). Then, the newly efficient firm acquires an obsolete one; this is welfare improving and profitable under the conditions of propositions $1-3$. Since the first step involves both a private and social gain, the welfare or profit hurdle for the second step ought to be easier to pass. However, the market structure is different at the start of the two steps so that no immediate conclusion is available.

\subsection{Innovation}

In our simple setting, rationalization is either production reshuffling with closure of the obsolete plant or knowledge diffusion with the upgrading of the obsolete plant towards the cutting-edge technology. The second interpretation being linked to innovation, it makes sense to contrast our previous findings with internal technical progress i.e., self-innovation.

When an obsolete firm succeeds to lower its marginal cost, the market structure becomes $n_{a}^{\prime}=n_{a}+1$ and $n_{b}^{\prime}=n_{b}-1$. We observe from formula (2) that $\Delta q_{a}=\Delta q_{b}=\frac{-\delta}{n+1}<0$ i.e., all firms but the innovative one produce less, yet $\Delta Q=\frac{\delta}{n+1}>0$ because the innovator increases its supply by $q_{a}-q_{b}=\delta$. Hence, the innovation favors consumer surplus. One cannot, however, conclude immediately that welfare increases since the technology upgrade intensifies market rivalry which hurts all the other firms. We thus need to compute exactly the welfare change. Using again (2) and denoting $z=M-c_{b}$, we have $q_{a}=\frac{z+\delta\left(n_{b}+1\right)}{n+1}, q_{b}=\frac{z-\delta n_{a}}{n+1}, q_{a}^{\prime}=\frac{z+\delta n_{b}}{n+1}$ and $q_{b}^{\prime}=$ 


$$
\begin{aligned}
\frac{z-\delta\left(n_{a}+1\right)}{n+1} \text { thus } & \\
(n+1)^{2} \Delta S & =\left(n_{a}(z+\delta)+n_{b} z+\frac{1}{2} \delta\right) \delta \\
(n+1)^{2} \Delta \Pi_{a} & =\left(n_{a}+1\right)\left(z+\delta n_{b}\right)^{2}-n_{a}\left(z+\delta\left(n_{b}+1\right)\right)^{2} \\
(n+1)^{2} \Delta \Pi_{b} & =\left(n_{b}-1\right)\left(z-\delta\left(n_{a}+1\right)\right)^{2}-n_{b}\left(z-\delta n_{a}\right)^{2}
\end{aligned}
$$

Letting $\Psi \equiv 2 n_{a}\left(n_{a}+2\right)-2 n_{b}\left(n_{b}+1\right)+1$, we obtain

$$
\Delta W \propto 2 z(n+2)-\delta \Psi=\left(M-c_{b}\right)\left(2(n+2)-\frac{\gamma \Psi}{2}\right) \quad \text { as } \gamma=\frac{2 \delta}{M-c_{b}}
$$

Hence the innovation is welfare improving if and only if $4(n+2)>\gamma \Psi$ which is true whenever $\Psi<0$ i.e., there are not so many efficient firms. To show that this still holds true when $\Psi>0$ (i.e., when $n_{a}$ is large), we use the fact that $\gamma<\frac{2}{n_{a}}$ (cf. (3)). We then only need to prove the sufficient condition $4(n+2)>\frac{2}{n_{a}} \Psi$ which, as one can check from the definition of $\Psi$, is trivially satisfied. It is only when several obsolete firms are forced to exit (violation of $(3)$ ) that welfare might drop because concentration jumps abruptly. We thus obtain: ${ }^{22}$

Proposition 5 Innovation by an obsolete firm towards the efficient technology is socially desirable and lowers the price.

The last possibility we consider is when two obsolete firms merge without any technological improvement. We have $n_{a}^{\prime}=n_{a}$ and $n_{b}^{\prime}=n_{b}-1$ since the new owner will use either of the two obsolete technologies (but not both). From a market outcome point of view, the disappearance of an obsolete firm is as if an advanced firm had bought it; hence the results of lemma 1 and proposition 1 regarding price and welfare remain valid. To see that such a merger is unprofitable, we study

$$
\chi \equiv \pi_{b}^{\prime}-2 \pi_{b} \propto\left(q_{b}+\Delta q_{b}\right)^{2}-2 q_{b}^{2}=\left(\left(1+\frac{1}{n}\right)^{2}-2\right) q_{b}^{2}
$$

and notice that $\chi<0 \Leftrightarrow n>2$. If there are only obsolete firms $\left(n_{a}=0\right)$, we fall back on the Salant et al. (1983) paradox when only a duopoly merging to monopoly is profitable. Otherwise, there is at least one efficient firm and at least the two merging obsolete ones, so that the condition holds. Our framework thus yields a more clear cut result than proposition 3 of Heubeck et al. (2006).

Proposition 6 A non innovative merger between two obsolete firms is unprofitable.

\footnotetext{
${ }^{22}$ A similar possibility is hinted at by Lahiri and Ono (1988).
} 


\section{Conclusion}

That a merger can increase market power and the productive efficiency of the industry at the same time is well understood. However, the impact on welfare of these opposing forces is hard to disentangle because they work at different levels. The market power offense is direct and easy to grasp: in the Cournot model of oligopolistic competition (as well as in most other IO models), higher concentration leads to a higher equilibrium price and a lower consumer surplus. The efficiency defense suffers from a more convoluted reasoning as it works indirectly: a merger bestows insiders with the opportunity to improve their technology, thus reduce their cost and become fiercer competitors. This tends to lower the price and generate profit gains that MAY overcome the aforementioned consumer surplus loss.

In this paper, we simplify the Farrell and Shapiro (1990) framework to pinpoint the necessary degree of efficiency improvement (rationalization) for the previous assertion to be true. We also make a methodological point by leveling the playing field between the market power offense and the efficiency defense regarding the welfare effects of mergers. Our framework, like most of the literature, employs the highly stylized Cournot model; needless to say, its implications for antitrust policy should be handled with care. Several limitations are worth mentioning.

Firstly, we take welfare to be the adequate social objective whereas consumer surplus was historically the focus of antitrust authorities; in that latter case, theoretical conclusions are clear-cut since a merger involving large firms and without significant synergies ought to be barred. Secondly, an obvious shortcoming of assuming constant marginal cost is that upon being acquired an obsolete firm is shut down and the only advantage for the acquirer is to reduce market rivalry. ${ }^{23}$ In real mergers, it is rare to see all the assets of the acquired firm being divested. Rather, inefficient plants are closed or re-organized with injections of human and physical capital. Thirdly, the linear Cournot model, even with asymmetric cost, tends to give similar market shares in equilibrium to all firms. The real impact of technological asymmetries is thus probably stronger but since it might increase both the "market power" and the "dynamic efficiency" effects of a merger, it remain difficult to sign. Fourthly, our analysis disregards fixed costs altogether which play a crucial part in the assessment of synergies and scale economies brought about by mergers. Fifth of all, we consider exogenous

\footnotetext{
${ }^{23}$ Because this property is a public good, outsiders to the merger free-ride on the insiders to the merger without having to support the cost.
} 
mergers and not endogenous one i.e., we do not allow for reactions such as entry or exit after mergers. Lastly, although we discourse at length about dynamic efficiency, our approach is static; it thus neglects the fact that concentration operations tend to facilitate collusion by reducing the number of people involved.

\section{Appendix}

\section{Properties of the Cournot equilibrium under asymmetric cost}

Let $D($.$) be the market demand and P($.$) its inverse, the willingness to$ pay. There are $n$ active firms with constant marginal cost $c_{i}$ for $i \leq n$. We denote $Q \equiv \sum_{i \leq n} q_{i}$ the aggregate output, $\epsilon \equiv \frac{-P}{Q P^{\prime}}$ the elasticity of demand, $H \equiv \sum_{i \leq n}\left(\frac{q_{i}}{Q}\right)^{2}$ the HHI concentration index, $\pi_{i}=q_{i}\left(p-c_{i}\right)$ the

individual profit, $\Pi \equiv \sum_{i \leq n} \pi_{i}$ the aggregate profit and $\bar{c} \equiv \frac{1}{n} \sum_{i \leq n} c_{i}$ the average marginal cost.

The FOC of profit maximization is

$$
P(Q)+q_{i} P^{\prime}(Q)=c_{i} \Rightarrow p-c_{i}=\frac{p q_{i}}{\epsilon Q}
$$

thus

$$
\pi_{i}=q_{i}\left(p-c_{i}\right)=\frac{p Q}{\epsilon}\left(\frac{q_{i}}{Q}\right)^{2} \Rightarrow \Pi=\frac{p Q}{\epsilon} H
$$

which is the Cowling and Waterson (1976) formula (notice that they use a model of quantity competition à la Cournot with conjectural variations).

FOC (14) also reads $\frac{q_{i}}{Q}=\epsilon \frac{p-c_{i}}{p}$, thus

$$
H=\epsilon^{2} \sum_{i \leq n}\left(\frac{p-c_{i}}{p}\right)^{2} \Rightarrow \frac{p^{2} H}{\epsilon^{2}}=\sum_{i \leq n}\left(p-\bar{c}+\bar{c}-c_{i}\right)^{2}=n(p-\bar{c})^{2}+n \sigma_{c}^{2}
$$

where $\sigma_{c}^{2}$ is the variance of the sample of marginal costs. Observe now that summing (14), we obtain $n(p-\bar{c})=\frac{p}{\epsilon}$. Plugging in (16), we get $\frac{p^{2} H}{\epsilon^{2}}=\frac{p^{2}}{n \epsilon^{2}}+n \sigma_{c}^{2}$, thus

$$
H=\frac{1}{n}+\frac{n \epsilon^{2} \sigma_{c}^{2}}{p^{2}}=\frac{1}{n}+\frac{(1-n \epsilon)^{2}}{n} v_{c}^{2}
$$

where $v_{c}$ is the coefficient of variation. This is the Clarke and Davies (1982) formula. 
Salant and Shaffer (1999) observe that summing the left version of (14), one gets $P(Q)+\frac{1}{n} Q P^{\prime}(Q)=\bar{c}$ i.e., aggregate output $Q$ and consumer surplus $S$ depend on $\bar{c}$ only. Now, by combining (15) and (17), we get $\frac{n \epsilon}{p Q} \Pi=1+(1-$ $n \epsilon)^{2} v_{c}$. When $\bar{c}$ is constant, so are $Q, p, \epsilon$, thus welfare $W=\Pi+S$ increases with dispersion of technologies. The limit is reached when a maximum number of firms are driven out of the market (or at least lose their economic rent) while the remaining ones achieve zero marginal cost, a result in the line of Cournot's observation regarding industry cost.

\section{Numerical Values for Thresholds}

For $n_{b}$ obsolete $(b)$ and $n_{a}$ cutting-edge $(a)$ firms, we have

\begin{tabular}{|l|r|r|r|r|r|r|r|r|}
\hline$n_{b}{ }^{n_{a}}$ & 1 & 2 & 3 & 4 & 5 & 6 & 7 & 8 \\
\hline 1 & 59 & 23 & 12 & 8 & 5 & 4 & 3 & 2 \\
\hline 2 & 45 & 18 & 10 & 7 & 5 & 4 & 3 & 2 \\
\hline 3 & 37 & 15 & 9 & 6 & 4 & 3 & 2 & 2 \\
\hline 4 & 31 & 13 & 8 & 5 & 4 & 3 & 2 & 2 \\
\hline 5 & 27 & 12 & 7 & 5 & 3 & 3 & 2 & 2 \\
\hline 6 & 24 & 11 & 6 & 4 & 3 & 2 & 2 & 2 \\
\hline \hline$\frac{2}{n_{a}}$ & 200 & 100 & 67 & 50 & 40 & 33 & 29 & 25 \\
\hline
\end{tabular}

Table 1: Minimum technology gap (in \%) for a welfare improving merger

\begin{tabular}{|l|r|r|r|r|r|r|r|r|}
\hline$n_{b} n_{a}$ & 1 & 2 & 3 & 4 & 5 & 6 & 7 & 8 \\
\hline 1 & $\underline{-18}$ & $\underline{14}$ & 23 & 24 & 23 & 22 & 20 & 18 \\
\hline 2 & $\underline{15}$ & 26 & 27 & 26 & 24 & 22 & 20 & 19 \\
\hline 3 & $\underline{30}$ & 32 & 30 & 27 & 25 & 22 & 20 & 19 \\
\hline 4 & 38 & 35 & 32 & 28 & 25 & 23 & 21 & 19 \\
\hline 5 & 43 & 38 & 33 & 29 & 26 & 23 & 21 & 19 \\
\hline 6 & 47 & 39 & 34 & 29 & 26 & 23 & 21 & 19 \\
\hline \hline$\frac{2}{n_{a}}$ & 200 & 100 & 67 & 50 & 40 & 33 & 29 & 25 \\
\hline
\end{tabular}

Table 2: Minimum technology gap (in \%) for a profitable merger

\section{References}

Bain J. Relation of profit rate to industry concentration: American manufacturing, 1936-1940. Quarterly Journal of Economics, 65(3):293-324, 1951. 
Banal Estañol A., Macho Stadler I., and Seldeslachts J. Endogenous mergers and endogenous efficiency gains: The efficiency defence revisited. International Journal of Industrial Organization, To appear, 2008.

Bartelsman E. J. and Doms M. Understanding productivity: Lessons from longitudinal microdata. Journal of Economic Literature, 38(3):569-95, 2000 .

Benchekroun H. and Chaudhuri A. R. Trade liberalization and the profitability of mergers: a global analysis. Review of International Economics, 14 (5):941-957, 2006.

Clarke R. and Davies S. Market structure and price-cost margins. Economica, 49(195):277-287, 1982.

Cournot A. Recherches sur les principes mathématiques de la théorie des richesses. Paris: Hachette, 1838.

Cowling K. and Waterson M. Price-cost margins and market structure. Economica, 43(171):267-74, 1976.

Daughety A. Beneficial concentration. American Economic Review, 80(5): 1231-7, 1990.

Davidson C. and Mukherjee A. Horizontal mergers with free entry. International Journal of Industrial Organization, 25(1):157-172, 2007.

Demsetz H. Industry structure, market rivalry and public policy. Journal of Law and Economics, 16:1-10, 1973.

Dewey D. Mergers and cartels: Some reservations about policy. American Economic Review (Papers and Proceedings), 51(2):255-262, 1961.

DoJ. Horizontal merger guidelines. Technical report, U.S. Department of Justice and the Federal Trade Commission, 1997.

EC. Horizontal merger guidelines. Technical report, European Commission, Competition Directorate, 2004.

Farrell J. and Shapiro C. Horizontal mergers: An equilibrium analysis. American Economic Review, 80(1):107-126, 1990.

Farrell J. and Shapiro C. Scale economies and synergies in horizontal merger analysis. Antitrust Law Journal, 68:685-710, 2001. 
Février P. and Linnemer L. Idiosyncratic shocks in an asymmetric cournot oligopoly. International Journal of Industrial Organization, 22(6):835848, 2004.

Foster L., Haltiwanger J., and Syverson C. Reallocation, firm turnover, and efficiency: Selection on productivity or profitability? American Economic Review, page in press, 2008.

Gugler K. and Siebert R. Market power versus efficiency effects of mergers and research joint ventures: Evidence from the semiconductor industry. The Review of Economics and Statistics, 89(4):645-659, 2007.

Gugler K., Mueller D. C., Yurtoglu B. B., and Zulehner C. The effects of mergers: an international comparison. International Journal of Industrial Organization, 21(5):625-653, 2003.

Heubeck S., Smythe D., and Zhao J. A note on the welfare effects of horizontal mergers in asymmetric linear oligopolies. Annals of Economics and Finance, 7(1), 2006.

Huck S., Konrad K., and Müller W. Profitable horizontal mergers without cost advantages: The role of internal organization, information and market structure. International Journal of Industrial Organization, 71(284): 575-587, 2004.

Kamien M. and Zang I. The limits of monopolization through acquisition. Quarterly Journal of Economics, 105(2):465-499, 1990.

Kovacic W. and Shapiro C. Antitrust policy: A century of economic and legal thinking. Journal of Economic Perspectives, 14(1):43-60, 2000.

Lahiri S. and Ono Y. Helping minor firms reduces welfare. Economic Journal, 98(393):1199-1202, 1988.

Levin D. Horizontal mergers: The 50-percent benchmark. American Economic Review, 80(5):1238-1245, 1990.

McGee J. In defense of industrial concentration. Praeger, New York, 1971.

Melitz M. J. The impact of trade on intra-industry reallocations and aggregate industry productivity. Econometrica, 71(6):1695-1725, 2003.

Motta M. and Vasconcelos H. Efficiency gains and myopic antitrust authority in a dynamic merger game. International Journal of Industrial Organization, 23(9-10):777-801, 2005. 
Neary P. Cross-border mergers as instruments of comparative advantage. Review of Economic Studies, 74(4):1229-1257, 2007.

Parisi J. J. A simple guide to the ec merger regulation. Technical report, FTC, 2007.

Peltzman S. The gains and losses from industrial concentration. Journal of Law and Economics, 20(2):229-264, 1977.

Pesendorfer M. Mergers under entry. RAND Journal of Economics, 36(3): 661-679, 2005.

Pesendorfer M. Horizontal mergers in the paper industry. The RAND Journal of Economics, 34(3):495-515, 2003.

Qiu L. and Zhou W. Merger waves: A model of endogenous mergers. RAND Journal of Economics, 38(1):214-226, 2007.

Salant S. W. and Shaffer G. Unequal treatment of identical agents in cournot equilibrium. American Economic Review (Papers and Proceedings), 89(3): 585-604, 1999.

Salant S. W., Switzer S., and Reynolds R. Losses from horizontal merger: The effects of an exogenous change in industry structure on cournot-nash equilibrium. Quarterly Journal of Economics, 98(2):185-99, 1983.

Schumpeter J. A. Capitalism, socialism and democracy. Harper \& Row, New York, 1942.

Spector D. Horizontal mergers, entry, and efficiency defences. International Journal of Industrial Organization, 21(10):1591-1600, 2003.

Stigler G. Monopoly and oligopoly by mergers. American Economic Review (Papers and Proceedings), 40(2):23-34, 1950.

Werden G. and Froeb L. The entry-inducing effects of horizontal mergers. Journal of Industrial Economics, 46(4):525-543, 1998.

Whinston M. Antitrust policy toward horizontal mergers, volume 3, chapter 36. Elsevier, 2007.

Williamson O. Economies as an antitrust defense: The welfare trade-offs. American Economic Review, 50(1):18-36, 1968. 


\section{Recent titles}

\section{CORE Discussion Papers}

2009/1. Carlo ROSA. Forecasting the direction of policy rate changes: The importance of ECB words.

2009/2. Sébastien LAURENT, Jeroen V.K. ROMBOUTS and Francesco VIOLANTE. Consistent ranking of multivariate volatility models.

2009/3. Dunia LÓPEZ-PINTADO and Juan D. MORENO-TERNERO. The principal's dilemma.

2009/4. Jacek B. KRAWCZYK and Oana-Silvia SEREA. A viability theory approach to a two-stage optimal control problem of technology adoption.

2009/5. Jean-François MERTENS and Anna RUBINCHIK. Regularity and stability of equilibria in an overlapping generations model with exogenous growth.

2009/6. Nicolas GILLIS and François GLINEUR. Using underapproximations for sparse nonnegative matrix factorization.

2009/7. Michel M. DENUIT, Louis EECKHOUDT and Mario MENEGATTI. Correlated risks, bivariate utility and optimal choices.

2009/8. Michel M. DENUIT, Louis EECKHOUDT and Mario MENEGATTI. Adding independent risks in an insurance portfolio: which shape for the insurers' preferences?

2009/9. Antoine BOMMIER and Stéphane ZUBER. The Pareto principle of optimal inequality.

2009/10. Raouf BOUCEKKINE, Jacek B. KRAWCZYK and Thomas VALLEE. Environmental negotiations as dynamic games: Why so selfish?

2009/11. Théophile T. AZOMAHOU, Raouf BOUCEKKINE and Phu NGUYEN-VAN. Promoting clean technologies under imperfect competition.

2009/12. Patrice PIERETTI and Skerdilajda ZANAJ. On tax competition, public goods provision and jurisdictions' size.

2009/13. Jeroen V.K. ROMBOUTS and Lars STENTOFT. Bayesian option pricing using mixed normal heteroskedasticity models.

2009/14. Gauthier de MAERE d'AERTRYCKE and Yves SMEERS. The valuation of power futures based on optimal dispatch.

2009/15. Thierry BRECHET, Tsvetomir TSACHEV and Vladimir M. VELIOV. Prices versus quantities in a vintage capital model.

2009/16. François VANDERBECK and Laurence A. WOLSEY. Reformulation and decomposition of integer programs.

2009/17. Marc FLEURBAEY, Erik SCHOKKAERT and Koen DECANCQ. What good is happiness?

2009/18. David DE LA CROIX and Michel LUBRANO. The tradeoff between growth and redistribution: ELIE in an overlapping generations model.

2009/19. Thierry BRECHET and Fabien PRIEUR. Can education be good for both growth and the environment?

2009/20. Giacomo SBRANA and Andrea SILVESTRINI. What do we know about comparing aggregate and disaggregate forecasts?

2009/21. Marc GERMAIN, Henry TULKENS and Alphonse MAGNUS. Dynamic core-theoretic cooperation in a two-dimensional international environmental model.

2009/22. Claude D'ASPREMONT and Rodolphe DOS SANTOS FERREIRA. Household behavior and individual autonomy.

2009/23. Helmuth CREMER, Philippe DE DONDER and Pierre PESTIEAU. Education and social mobility.

2009/24. Maria Eugenia SANIN and Francesco VIOLANTE. Understanding volatility dynamics in the EU-ETS market: lessons from the future.

2009/25. Marco DI SUMMA and Laurence A. WOLSEY. Lot-sizing with stock upper bounds and fixed charges.

2009/26. Johanna M.M. GOERTZ and François MANIQUET. On the informational efficiency of simple scoring rules.

2009/27. Jean GABSZEWICZ, Ornella TAROLA and Skerdilajda ZANAJ. On uncertainty when it affects successive markets. 


\section{Recent titles}

\section{CORE Discussion Papers - continued}

2009/28. Jerzy A. FILAR, Jacek B. KRAWCZYK and Manju AGRAWAL. On production and abatement time scales in sustainable development. Can we loosen the sustainability screw?

2009/29. María Eugenia SANIN and Skerdilajda ZANAJ. Clean technology adoption and its influence on tradeable emission permit prices.

2009/30. Antoine BOMMIER, Marie-Louise LEROUX and Jean-Marie LOZACHMEUR. On the public economics of annuities with differential mortality.

2009/31. Gilles GRANDJEAN, Ana MAULEON and Vincent VANNETELBOSCH. Connections among farsighted agents.

2009/32. Axel GAUTIER and Xavier WAUTHY. On the nature of price competition under universal service obligations: a note.

2009/33. Santanu S. DEY and Laurence A. WOLSEY. Constrained infinite group relaxations of MIPs.

2009/34. Jean-François MAYSTADT and Philip VERWIMP. Winners and losers among a refugeehosting population.

2009/35. Pierre DEHEZ. Allocation of fixed costs and the weighted Shapley value.

2009/36. Sabien DOBBELAERE, Roland Iwan LUTTENS and Bettina PETERS. Starting an R\&D project under uncertainty.

2009/37. Carlotta BALESTRA and Davide DOTTORI. Aging society, health and the environment.

2009/38. Alain PHOLO BALA. Urban concentration and economic growth: checking for specific regional effects.

2009/39. Alain PHOLO BALA. Gates, hubs and urban primacy in Sub-Saharan Africa.

2009/40. Nicolas BOCCARD. On efficiency, concentration and welfare.

\section{Books}

H. TULKENS (ed.) (2006), Public goods, environmental externalities and fiscal competition. New York, Springer-Verlag.

V. GINSBURGH and D. THROSBY (eds.) (2006), Handbook of the economics of art and culture. Amsterdam, Elsevier.

J. GABSZEWICZ (ed.) (2006), La différenciation des produits. Paris, La découverte.

L. BAUWENS, W. POHLMEIER and D. VEREDAS (eds.) (2008), High frequency financial econometrics: recent developments. Heidelberg, Physica-Verlag.

P. VAN HENTENRYCKE and L. WOLSEY (eds.) (2007), Integration of AI and OR techniques in constraint programming for combinatorial optimization problems. Berlin, Springer.

P-P. COMBES, Th. MAYER and J-F. THISSE (eds.) (2008), Economic geography: the integration of regions and nations. Princeton, Princeton University Press.

J. HINDRIKS (ed.) (2008), Au-delà de Copernic: de la confusion au consensus ? Brussels, Academic and Scientific Publishers.

\section{CORE Lecture Series}

C. GOURIÉROUX and A. MONFORT (1995), Simulation Based Econometric Methods.

A. RUBINSTEIN (1996), Lectures on Modeling Bounded Rationality.

J. RENEGAR (1999), A Mathematical View of Interior-Point Methods in Convex Optimization.

B.D. BERNHEIM and M.D. WHINSTON (1999), Anticompetitive Exclusion and Foreclosure Through Vertical Agreements.

D. BIENSTOCK (2001), Potential function methods for approximately solving linear programming problems: theory and practice.

R. AMIR (2002), Supermodularity and complementarity in economics.

R. WEISMANTEL (2006), Lectures on mixed nonlinear programming. 